\title{
Ética en dermatología
}

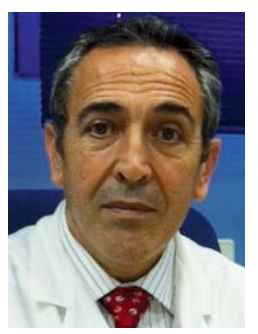

Sixto López Martín Director médico. Capio Hospital de Día de Talavera de la Reina. Toledo
Durante más de 3500 años, nuestra profesión ha fundamentado sus postulados éticos en el paternalismo, es lo que conocemos como el paradigma ético clásico. El sustrato eran las teorías éticas que consideramos como principales (ética de la virtud, consecuencialismo y utilitarismo). Será en 1979 cuando Beauchamp y Childress, recogiendo lo que ya era una corriente imparable de contestación a lo establecido, publiquen su libro Principios de Ética Biomédica, máximo exponente de lo que conocemos como ética de los principios que, combinando las teorías consecuencialistas y utilitaristas, aplica unos principios asumibles por la mayoría de los individuos de una sociedad pluralista. Justificará esta nueva teoría el cambio de paradigma, al ser tomados los principios que enuncia (no maleficencia, beneficencia, justicia y autonomía) como base para la toma de decisiones en la práctica clínica diaria y para el análisis de la eticidad de los actos médicos. Pero, como decimos más arriba, el cambio había empezado antes.

En España, a partir de la década de los cincuenta, comienza a desarrollarse un sistema sanitario que puede considerarse entre los mejores del mundo. En este sistema, la dermatología se asienta, al igual que otras especialidades médicas consideradas hasta ese momento «menores», como una ciencia fundamental en la moderna medicina española. Por esas mis- mas fechas, se producía, en países democráticos del mundo occidental, la crisis del paradigma ético clásico de la profesión médica, a la par que comenzaban a dibujarse los trazos de uno nuevo. La verdad es que los médicos, y sus organizaciones corporativas, tuvieron poco protagonismo en esa crisis y en las consecuencias que de ella se derivaron y fueron a remolque de los acontecimientos. Hubieron de ser los tribunales de justicia en los EE.UU. de América y los movimientos defensores de los derechos civiles los que pusieran en marcha una imparable dinámica que llevaría a que el paternalismo médico comenzara a declinar ante una nueva actitud ética cimentada en el respeto a la libertad del individuo, para poder elegir lo que quiere hacer con su cuerpo y su salud. Las atrocidades llevadas a cabo en los campos de concentración nazis, puestas de manifiesto en el juicio de Nuremberg, y la aparición de la bioética, entre otras cosas, desequilibrarán definitivamente el fiel de la balanza. Ya nada volverá a ser igual.

Como ya hemos relatado en otro lugar (Ética y Deontología Médica, Editorial Marban, Madrid, 2011), el sistema sanitario español que se desarrolla, en cantidad y calidad, desde la década de los sesenta y la corporación médica no supieron o no pudieron asumir el cambio de paradigma. Hemos de citar en su defensa los tímidos intentos que, desde la dirección del antiguo INSALUD y, en menor medi- 
da, desde el propio Ministerio de Sanidad, se hicieron, tratando de respetar, dentro de la ortodoxia política imperante, la autonomía del paciente. Los dirigentes de la Organización Médica Colegial española también eran políticamente correctos, virtud que en nuestros días siguen practicando con auténtico deleite, y tampoco hicieron nada que supusiera romper con las líneas establecidas del paternalismo imperante. Esta actitud se refleja en la publicación, en 1943, de las Bases para la redacción de un Código de Deontología Médica y en la presencia y participación en los sucesivos estatutos de la profesión médica de 1945 y 1967. Cuando, en 1968, se deroga este último, se harán esfuerzos infructuosos para redactar un código.

Será en 1976 cuando, nacido el actual régimen político, se crea la Comisión Central de Deontología y Derecho Médico y comienzan a sentarse las bases de un nuevo horizonte ético en la medicina española. El 23 de abril de 1979, se sanciona el Código de Ética y Deontología Médica de la España democrática. El nuevo paradigma ético de la profesión médica comienza a sustanciarse de forma oficial. Cinco meses antes habíamos aprobado en referéndum la Constitución, que será la fuente del derecho de las sucesivas leyes nacionales y autonómicas que regularán esta nueva forma de afrontar el ejercicio profesional médico. El día 4 de abril de 1997, los países integrantes de la Unión Europea firman en la ciudad de Oviedo el Convenio Relativo a los Derechos Humanos y la Biomedicina, norma de carácter supranacional que viene a obligar a las naciones integrantes y a las que en el futuro se integren a adaptar su legislación en materia médica y de investigación a unas reglas fundamentadas en el respeto a la libertad individual consagradas en este convenio. En España, entrará en vigor el 1 de enero de 2000 y, a partir de esa fecha, se producirán los cambios legislativos necesarios, a nivel nacional y autonómico, para dar cumplimiento a lo contenido en este llamado Convenio de Oviedo. Con el código, se hará igual.
Y esta es, muy a vuela pluma, la evolución de los tres pilares que soportan y regulan el ejercicio de la profesión médica: la ética, la deontología y las leyes. Y decimos ejercicio de una profesión, no de un oficio. Probablemente, la más hermosa de cuantas existen. Pero ejercicio, no lo olvidemos, que es un compromiso público de servicio a la sociedad de la que formamos parte, ante la que gozamos, en el nuevo paradigma, no de una moralidad especial como ocurría en el clásico, sino que estamos acogidos a la moral común con unos rasgos diferenciadores, puesto que se nos han entregado los rudimentos científicos del conocimiento de las claves que rigen bienes primarios como son la vida, el sufrimiento humano y la muerte de los que son iguales a nosotros.

Y este cambio de paradigma ¿se ha sustanciado en el ejercicio actual de la dermatología? No lo sabemos. Como mucho, tenemos el pálpito, pero lo que se dice saberlo, no lo sabemos.

¿Qué conocimientos en ética, deontología y leyes tienen los dermatólogos españoles? Hoy conviven, al menos, dos formaciones distintas en cuanto a estos aspectos se refiere: los antiguos, que no recibieron, en la formación reglada de la licenciatura, la asignatura de Ética y Deontología Médica, y los más modernos, cuyos planes de estudio, ya fuera como obligatoria u optativa, sí la integraban. Hay una asimetría en la formación, pues los primeros, si es que la tienen, se la han procurado por sí mismos, mientras que los segundos, en cambio, se supone que la recibieron en la facultad. ¿En qué fundamentación ética se mueve el dermatólogo? ¿Ética de la virtud, utilitarismo, consecuencialismo, ética de los principios u otra de las llamadas menores?

¿Qué inquietudes y preocupaciones éticas tiene el dermatólogo español? Tampoco lo sabemos. Consideramos que cuestiones tales como la formación técnica y ética, la formación continuada, los honorarios profesionales, etc. nos preocupan a todos. Pero, ¿es así?

Ya he definido en otro lugar los niveles de conflicto ético: un primer nivel en el que el médico 
aporta la información pero no participa en la decisión; un segundo nivel en el que hace esto y, además, de forma directa o indirecta, participa en la decisión, y un tercer nivel en el que tiene que decidir sobre la marcha y, a veces, en solitario y de forma rápida. Este último es el más importante, entre otras cosas porque recoge la mayoría de los conflictos éticos que al dermatólogo se le plantean en el ejercicio diario. Es lo que llamo la ética de los problemas diarios. ¿Y cómo resuelve el dermatólogo los problemas éticos diarios que su actividad suscita? ¿Cómo resuelve la relación con el paciente del que le separa idioma, cultura y valores? ¿Qué hace el dermatólogo católico a la hora de indicar un tratamiento con ácido retinoico a una mujer fértil que debe ir acompañado de anticoncepción? ¿Y si el católico es la paciente? ¿Y el problema clínico calificado de estético si el sistema le prohíbe abordarlo? ¿Está seguro de que el no abordaje no va a causar un trastorno psíquico a su paciente? ¿Quién decide la elección de tratamientos alternativos, si los hubiere? ¿Y del consentimiento informado, qué? ¿Y la comunicación de diagnóstico y/o pronóstico fatal? Y en otro orden de cosas: ¿cómo están afectando al ánimo del dermatólogo y, consecuentemente, a su ejercicio profesional las medidas que el sistema está tomando sobre horas, organización del trabajo y honorarios profesionales? ¿Considera el dermatólogo que estas medidas salvarán el sistema o, por el contrario, cree que lo único que hacen es alargar la agonía de este? ¿Cómo responde ante este reto ético? En fin, podríamos llenar las siguientes páginas de preguntas, cuyas respuestas solo las tiene el dermatólogo en ejercicio. No hay estudios en este sentido. Los hay parciales en otras áreas médicas, pero en dermatología clínica, no. Y es preciso saber si la dermatología española ha asumido o no el nuevo paradigma ético de la profesión. El nivel técnico y científico de nuestra dermatología es equiparable al de los países más avanzados, pero desconocemos si, habiendo cambiado la sociedad, las organizaciones médicas y las leyes, lo ha hecho el dermatólogo español, adaptando sus postulados éticos al nuevo paradigma. 